\title{
TYK2 Fusion Positive
}

National Cancer Institute

\section{Source}

National Cancer Institute. TYK2 Fusion Positive. NCI Thesaurus. Code C157590.

An indication that expression of a fusion containing sequences from TYK2 has been detected in a sample. 